\title{
Acid secretory response to graded doses of histamine after 'medical vagotomy'
}

\author{
S. RAJU AND F. M. NARIELVALA \\ From the Peptic Ulcer Research Unit and Department of Medicine (Gastroenterology), \\ Christian Medical College, Vellore, S. India
}

EDITORIAL COMMENT The oxyntic cell becomes less responsive to histamine after vagotomy and this is the subject of this present study.

Experimental science has focused attention on the physiological effects of vagotomy in animals since the Pavlovian era. Vagotomy had been practised for various vague 'nervous' or so-called 'functional' disorders from 1911 onwards. It was, however, only as late as 1943 that this operation for chronic duodenal ulceration was reported by Dragstedt in a small series of cases. The sound physiological reasons propounded by Dragstedt by which the operation reduces acid secretion significantly has increasingly popularized this operation for chronic duodenal ulcer.

The reduction in gastric acid output following vagotomy can be convincingly demonstrated by the augmented histamine test (Gillespie, Clark, Kay, and Tankel, 1960; McArthur, Tankel, and Kay, 1960; and Kyle and Stephens, 1961), and similar reduction in acid output has been induced with the vagolytic drugs, atropine and hexamethonium, given parenterally, in studies carried out on duodenal ulcer patients by McArthur et al. (1960) and Gillespie and Kay (1961). This pharmacological interruption of vagal stimulus has been called 'medical vagotomy' (Kay and Smith, 1956). The fall in acid output, as determined by the augmented histamine test after medical vagotomy, demonstrates a physiological dependence and inter-relationship between the vagus and histamine which has been generally accepted as the final denominator for stimulation of the parietal cells and the parietal cell mass (Code, 1956; Smith, 1961).

\section{MATERIALS AND METHODS}

Eight adult male subjects were selected having a radiologically proven diagnosis of chronic duodenal ulcer without any evidence of pyloro-duodenal obstruction. The initial augmented histamine test revealed in these subjects high volumetric and acid outputs for the basal (B.A.O.) and post-histamine or maximal (M.A.O.) collections. This was advantageous so that the depressed gastric secretion after 'medical vagotomy' could still yield volumes for easy and accurate measurement.

An initial augmented histamine test (Kay, 1953) as modified by Card and Marks (1960), was performed in all the eight subjects using the conventional four 'body weight' doses of histamine $(0.04 \mathrm{mg}$. per $\mathrm{kg}$. of body weight). Thereafter a medical vagotomy test was carried out as follows (Gillespie and Kay, 1961):

After the patient had fasted overnight the resting gastric content was aspirated through a radio-opaque 16 Fr. gauge Levin's tube which was positioned optimally under fluoroscopic control. Hexamethonium bromide, $50 \mathrm{mg}$., and atropine sulphate, $0.325 \mathrm{mg}$. was then administered parenterally as a single intramuscular injection. Following this, continuous gastric aspiration with Steadmann's pump was undertaken for an hour and a half, consisting of six 15-minute samples. This invariably yielded an absence of free acid in the fourth 15-minute sample. At this stage, histamine stimulation was employed, preceded by a protective antihistamine injection (Anthisan or mepyramine maleate intramuscularly half an hour before the histamine). Further collection of gastric secretion by continuous suction gave the posthistamine acid output which also consisted of four 15minute samples, according to the standard augmented histamine test procedure.

Acid estimations were carried out by titration as in the standard augmented histamine test.

A number of such tests under the influence of medical vagotomy were carried out in each subject with varying amounts of histamine. This entailed four, six, eight, and 10 body-weight doses of histamine in order to elicit a 'dose response curve' (one body weight dose $=0.01 \mathrm{mg}$. of histamine per $\mathrm{kg}$. of body weight). The prior antihistaminic injection also varied at the rate of $25 \mathrm{mg}$. of Anthisan for two body weight doses of histamine in order to ensure adequate protection from possible undesirable side-effects of the increased doses of histamine. An interval of not less than five days was allowed between two consecutive tests in each subject so as to eliminate cumulative effects, if any, of the vagolytic regimen. The method of carrying out each test was strictly adhered to 
and the background conditions were kept as constant as possible with reference to a particular subject. The series of tests had only the above-mentioned variation in the scheme of doses. Nevertheless the possibility of a patient getting used to the tests and/or the possible emergence of tolerance to the vagolytic drugs given repeatedly had to be considered as possibly introducing non-specific elements of error in to the overall results. An attempt was made to anticipate this problem by varying the order of the dose schedule of histamine from subject to subject (Table I).

\section{TABLE I}

HISTAMINE DOSE SCHEDULE ACCORDING TO BODY WEIGHT IN EIGHT SUBJECTS

\begin{tabular}{lrrrrrrrrr} 
Test & \multicolumn{1}{l}{ Subject } \\
\cline { 2 - 8 } & K.A. & V.E. & Z.A. & G.O. & R.A. & S.A. & G.P. & J.B. \\
\hline 1 & 4 & 6 & 4 & 4 & 4 & 6 & 8 & 8 \\
2 & 8 & 10 & 6 & 6 & 8 & 8 & 6 & 10 \\
3 & 6 & 8 & 8 & 8 & 10 & 10 & 4 & 4 \\
4 & 10 & 4 & 10 & 10 & 6 & 4 & 10 & 6
\end{tabular}

\section{RESULTS}

There were no serious side-effects to the drugs used in any of the eight subjects. Varying degrees of mild to moderate transient hypotension were, however, recorded. Headache and somnolence were observed in all during and/or after the tests for a short period.

The fall in the post-histamine hourly acid output following medical vagotomy has been expressed as a fraction (percentage) of the initial value obtained without the vagolytic drugs in Table II.

In seven cases a reduction of not less than $45 \%$ was obtained. In one patient (V.E.), however, the fall was only of the order of $27 \%$. With each further increment in the dose of histamine the acid output was increased in all the subjects (Fig. 2). Under the influence of 10 body-weight doses of histamine the pre-vagotomy level of acid output (M.A.O.) was exceeded in one subject (V.E.), while in another (S.A.) it almost returned to the initial figure. In all the other six subjects significant but varying degrees of
TABLE II

PERCENTAGE REDUCTION IN POST-HISTAMINE ACID OUTPUT FOLLOWING MEDICAL VAGOTOMY WITH FOUR AND 10 BODY WEIGHT DOSES OF HISTAMINE

\begin{tabular}{llllllll}
$\begin{array}{l}\text { Percentage } \\
\text { Reduction after } \\
\begin{array}{l}\text { Medical } \\
\text { Vagotomy }\end{array}\end{array}$ & Subject & & & & & \\
\hline
\end{tabular}

Four body

weight doses of

\begin{tabular}{|c|c|c|c|c|c|c|c|}
\hline histamine 73 & 73 & 27 & 47 & 64 & 54 & 46 & 68 \\
\hline $\begin{array}{l}\text { Ten body } \\
\text { weight doses of } \\
\text { histamine } 46\end{array}$ & 37 & $-27^{1}$ & 18 & 39 & 44 & 1 & 40 \\
\hline
\end{tabular}

increased acid output were seen though the prevagotomy level was not attained even with the 10 body-weight dose. Acid secretion values before and after medical vagotomy, the latter for four and $\mathbf{1 0}$ body-weight doses of histamine, in the eight subjects are presented in Figure 1.

The 'dose-response curves' for each of the eight subjects with regard to acid secretion evoked by the augmented histamine test increasing the histamine up to 10 body-weight dosage after medical vagotomy are shown in Figure 2. The 'dose-response curve' suffers a quantitative change which nevertheless seems to vary from subject to subject. In two subjects (R.A. and Z.A.) the curve levels off at the six bodyweight dose level, whereas in the other six the curve continues to climb.

\section{DISCUSSION}

The effects of the vagolytic drugs used in this study were investigated in detail by Kay and Smith (1956). Atropine appears to exert a biphasic action, an initial stimulant component probably centrally mediated with a subsequent parasympatholytic effect peripherally executed. The former stimulating effect appears to be suppressed by the ganglion-blocking agent, hexamethonium. An appropriate synergism with marked inhibition of gastric secretion and

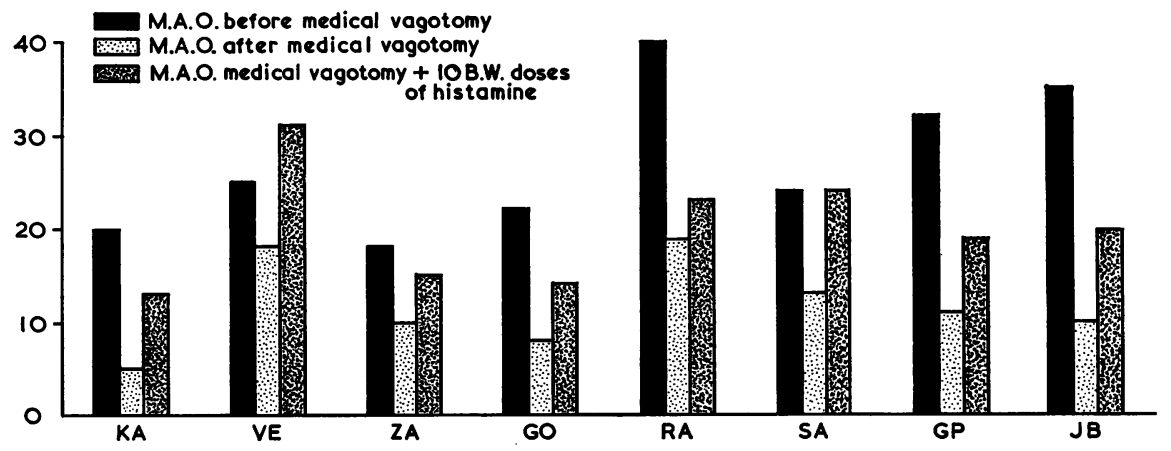

FIG. 1.

Acid secretion values before and after medical vagotomy. 


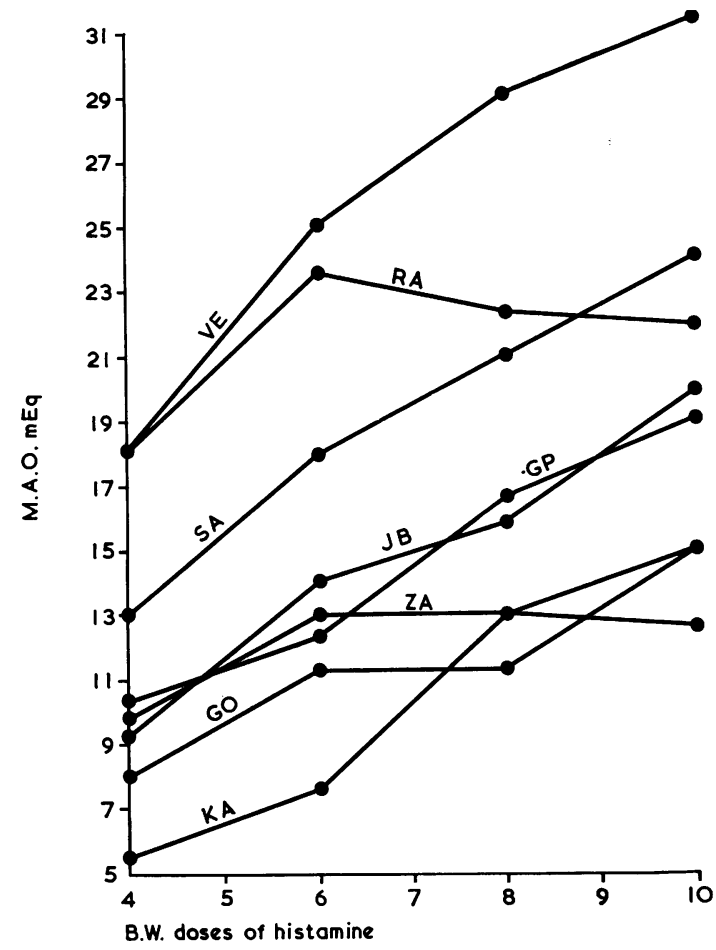

FIG. 2. Dose-response curves for eight subjects for acid secretion evoked by the augmented histamine test.

motility was observed with the combination of the drugs.

The results indicate that the oxyntic cell becomes less responsive to histamine in the absence of vagal influence, demanding larger doses of histamine. While four body-weight doses elicit a maximal response (Kay, 1953), normally, this is no longer so with vagal blockade; more than four body-weight doses appear to be necessary to be of maximal stimulus in the new situation. In fact, six of the eight subjects studied did not show a maximal response even with 10 body-weight doses of histamine as shown by their rising dose response curves (Fig. 2). Thus the term 'maximal acid output', used in the context of medical vagotomy as a response to four body-weight doses of histamine, is a misnomer. In two subjects (Z.A. and R.A.) the dose response curve reached a plateau at six body-weight dose levels and can be considered 'maximal acid output' with reference to medical vagotomy. This is still far short of the original M.A.O. values (Table II). Probably diminished sensitivity of the parietal cell only partly explains the reduction in acid output following vagolysis, and other factors also play a part.

The acid secretory values in one patient (V.E.) call for special comment. This is the only subject in the series whose pre-vagotomy acid output (M.A.O.) has been exceeded in the medical vagotomy test with 10 body-weight doses of histamine. The difference is of the order of $27 \%$. It is interesting to note that in this patient a reduction of only $27 \%$ was obtained in the acid output following vagal blockade, which is by far the least in the group (Table II). Thus this patient seems to belong to the category in which the hormonal (gastrin) influence is dominant over the nervous (vagal) component (Gillespie and Kay, 1961; Kay, 1962).

It is difficult to determine whether the mechanism and pharmacodynamics of acid secretion obtaining with medical vagotomy would not be dissimilar to that following surgical vagolysis. A satisfactory correlation between the two modes of vagal interruption or their effect on acid output has been demonstrated (McArthur et al., 1960), and has been utilized to predict the individual usefulness of surgical vagotomy as a therapeutic measure for chronic duodenal ulcer (Gillespie and Kay, 1961; Kay, 1962). Payne and Kay (1962) in a detailed study have shown that the parietal cell after surgical vagotomy exhibits a diminished responsiveness to histamine due to a reduction in available acetylcholine while increasing doses of histamine alone over and above four body-weight doses produced no significant rise in acid secretory response.

Since histamine has been given subcutaneously throughout the study, no attempt has been made to analyse in detail the dose response curves obtained, as these suffer from obvious limitations. But even with subcutaneous administration of histamine the familiar sigmoid dose response curve has been elicited (Kay, 1953). Therefore, certain generalizations can be made on the information available from the present study. With vagolysis a shift of the curve to the right is produced (Fig. 3), signifying a quantitative change in the relationship between the dosage of histamine and acid output. With the range of histamine doses employed in the present study and the resultant dose response curves, it has not been possible to determine whether a qualitative variation in the nature of the usual sigmoid curve takes place after medical vagotomy.

Histamine has been generally believed to act directly on the parietal cell (Code, 1956). If this were so it is puzzling why there should be a reduced response to the augmented histamine test after vagotomy. The drainage procedure after surgical vagotomy only partly explains the fall in acid output (Tankel, Gillespie, Clark, Ray, and McArthur, 1960). Various hypotheses, with some experimental support, have been put forward besides the one advanced in the present study (diminished sensitivity of the dener- 


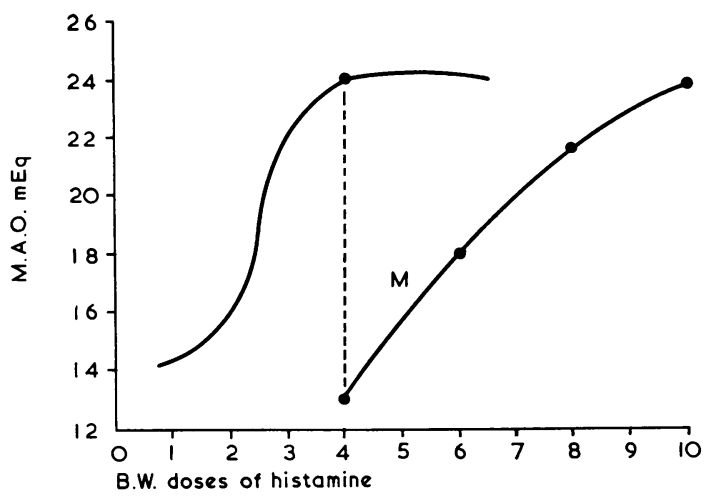

FIG. 3. Curve illustrating change in the relationship between the dosage of histamine and acid output.

vated parietal cell). Thus there is some evidence that the mechanism of the 'vagal permissive background' (Payne and Kay, 1962; Kay, 1962) may be partly responsible for the reduction in acid output in the vagotomized patient. A 'trophic influence' of the vagus on the parietal cell and a consequent hypoplasia of the denervated cell has been considered, but has been discounted on the basis of experimental and histological proof (Payne and Kay, 1962; Melrose, Russell, and Dick, 1964). There are also arguments against the reduction in acid output being explained on the basis of vascular changes induced by vagal section (Clark, Curnow, Murray, Stephens, and Wyllie, 1964). The very concept of histamine as a specific chemostimulator of the oxyntic cell has been called in question on the basis of a recent study by Clark et al. (1964). It has been suggested that histamine may indeed act through the vagus in a fashion similar to that of insulin. The intricacies of the physiology of acid secretion are far from clear despite voluminous work which often has yielded conflicting results (Hanson, Grossman, and Ivy, 1948; Code, Hightower, and Hallenbeck, 1951; Ivy and Farrell, 1925; Necheles, Motel, Kosse, and Neuwelt, 1938). A much more careful study seems to be necessary for the proper elucidation of an admittedly complex mechanism.

\section{REFERENCES}

Card, W. I., and Marks, I. N. (1960). The relationship between the acid output of the stomach following 'maximal' histamine stimulation and the parietal cell mass. Clin. Sci., 19, 147-163.

Clark, C. G., Curnow, J. V., Murray, J. G., Stephens, F. O., and Wyllie, J. H. (1964). Mode of action of histamine in causing gastric secretion in man. Gut, 5, 537-545.

Code C. F. (1956). Histamine and gastric secretion. In Ciba Foundation Symposium on Histamine, edited by G. E. W. Wolstenholme and C. M. O'Connor, pp. 189-219. Churchill, London.

- - Hightower, N. C. Jr., and Hallenbeck, G. A. (1951). Comparison of the effects of methantheline bromide (banthine) and atropine on the secretory responses of vagally innervated and vagally denervated gastric pouches. Gastroenterology, 19, 254-264.

Gillespie, I. E., Clark, D. H., Kay, A. W., and Tankel, H. I. (1960). Effect of antrectomy, vagotomy with gastrojejunostomy, and antrectomy with vagotomy on the spontaneous and maximal gastric acid output in man. Ibid., 38, 361-367.

_- and Kay, A. W. (1961). Effect of medical and surgical vagotomy on the augmented histamine test in man. Brit. med. J., 1, 15571560.

Hanson, M. E., Grossman, M. I., and Ivy, A. C. (1948). Doses of histamine producing minimal and maximal secretory responses in dog and man. Amer. J. Physiol., 153, 242-258.

Ivy, A. C., and Farrell, J. I. (1925). Contributions to the physiology of gastric secretion. VIII. The proof of a humoral mechanism Ibid., 74, 639-649.

Kay, A. W. (1953). Effect of large doses of histamine on gastric secretion of $\mathrm{HCl}$. Brit. med. J., 2, 77-80.

- (1962). Gastrointestinal surgery and human physiology. J. roy. Coll. Surg. Edinb., 7, 275-288.

- and Smith, A. N. (1956). The action of atropine and hexamethonium in combination on gastric secretion and motility. Brit. J. Pharmacol., 11, 231-235.

Kyle, J., and Stephens, F. (1961). Gastric acidity after duodenal ulcer surgery. Brit. J. Surg., 48, 465.

McArthur, J., Tankel, H. I., and Kay, A. W. (1960). A comparison between the effects of hexamethonium and atropine in combination and of vagotomy with gastrojejunostomy on human gastric secretion. Gut, 1, 230-236.

Melrose, A. G., Russell, R. I., and Dick, A. (1964). Gastric mucosal structure and function after vagotomy. Ibid., 5, 546-549.

Necheles, H., Motel, W. G., Kosse, J., and Neuwelt, F. (1938). The effects of acetylcholine, acetylbetamethylcholine and prostigmine on the secretion of the stomach of man and dog. Amer.J. dig. Dis., 5, 224-231.

Payne, R. A., and Kay, A. W. (1962). The effect of vagotomy on the maximal acid secretory response to histamine in man. Clin. Sci., 22, 373-382.

Smith, A. N. (1961) Histamine and gastric secretion. J. roy. Coll. Surg. Edinb., 6, 276-291.

Tankel, H. I., Gillespie, I. E., Clark, D. H., Kay, A. W., and McArthur J. (1960). A clinical and statistical study of the effect of Gastrojejunostomy on human gastric secretion. Gut, 1, 223-229. 